\title{
Pendugaan Pola Genetik dan Fenotipik Sifat Reproduksi Ternak Babi di Provinsi Bali
}

\author{
Estimation of Genetic and Phenotypic Trends of Reproduction Traits on Pig in Bali Province \\ N. K. Pati ${ }^{1)}$ A. Gunawan ${ }^{2)}$ \& R. I. Arifiantini ${ }^{3)}$ \\ ${ }^{1)}$ Mahasiswa Program Studi Ilmu Produksi dan Teknologi Peternakan, Sekolah Pascasarjana, IPB \\ ${ }^{2}$ Departemen Ilmu Produksi dan Teknologi Peternakan, Fakultas Peternakan, IPB \\ ${ }^{3}$ Departemen Klinik, Reproduksi dan Patologi, Fakultas Kedokteran Hewan, IPB \\ Jln. Agatis, Kampus IPB Dramaga Bogor 16680, Indonesia
}

\begin{abstract}
The aim of this study was to estimate genetic parameters on reproduction traits such as litter size, preweaning mortality and the number of piglet weaned. The data used were obtained from Artificial Insemination (AI) unit Baturiti. Estimation of breeding values were calculated with heritability and differensial selection. Genetic and phenotypic trends analysis were performed with the regression mean breeding values on birth year and mean phenotypic on birth year. According to the breeding value estimated for all traits, the best was the sire no. 32, whose breeding value for litter size, mortality and number weaned were $+0.27,+0.01$, and +0.35 . The highest genetic and phenotypic correlation were obtained between litter size and number of piglet weaned were 0.91 and 0.92 respectively. Genetic trends of litter size and number piglet weaned showed a similar pattern in 2010 to $\mathbf{2 0 1 5}$ were fluctuative then declined in $\mathbf{2 0 1 6}$, whereas the preweaning mortality tend to be stable. The phenotypic trends of litter size and the number of piglet weaned from 2010 through 2016 have the same pattern, which has a fluctuative pattern and lead to decrease in 2016. The phenotypic trend of preweaning mortality showed a stable pattern. The results of this research indicated that the reproduction traits of pig in Bali Province could be improve through selection programme.
\end{abstract}

Keywords: genetic trends, pig, reproduction traits

\section{PENDAHULUAN}

Sifat reproduksi ternak babi seperti litter size, mortalitas pra sapih, dan jumlah anak yang disapih adalah salah satu sifat yang paling ekonomis dan penting dalam program pemuliaan ternak babi saat ini (Dube et al. 2012; Kasprzyk 2007). Nilai heritabilitas pada ketiga sifat tersebut seperti yang dilaporkan Lukac dan Vidovic (2013); Zhu et al. (2008); Ziedina et al. (2011) dan tergolong rendah. Lukac dan Vidovic (2013) melaporkan heritabilitas sifat litter size dan jumlah anak yang disapih memiliki nilai yang sama yaitu 0,11 pada persilangan empat bangsa babi. Sedangkan nilai heritabilitas sifat mortalitas pra sapih menurut laporan Zhu et al. dan Ziedina et al. pada dua bangsa babi lokal China dan Landrace masing-masing sebesar 0,03 dan 0,08. Kizlinger et al. (2013) menyatakan nilai heritabilitas yang rendah akan menghasilkan peningkatan mutu genetik yang rendah. Gunawan dan Jakaria (2011) menyatakan bahwa sifat yang memiliki nilai heritabilitas sedang hingga tinggi akan lebih efektif dan efisien melalui program seleksi dalam upaya perbaikan mutu genetik. Namun seleksi juga dapat dilakukan pada sifat-sifat yang berkorelasi tinggi secara genetik dan fenotipik (Kizlinger et al. 2013).

Perbaikan mutu genetik yang optimum dapat dicapai melalui seleksi pada ternak berdasarkan beberapa parameter genetik diantaranya nilai pemuliaan dan korelasi genetik (Gunawan dan Jakaria 2011). Untuk memaksimalkan respon genetik untuk sifat yang diinginkan maka ternak unggul dengan nilai pemuliaan tertinggi harus diidentifikasi secara akurat (Newcom 2005). Keakuratan pendugaan parameter genetik penting untuk menentukan arah perbaikan mutu genetik (Lee et al. 2015).

Zishiri et al. (2010) menyatakan bahwa pola genetik yang pada suatu populasi ternak mencerminkan perubahan genetik terjadi periode tertentu. Pola genetik pada sifat reproduksi perlu dimonitor untuk mengetahui perubahan genetik yang terjadi (Dube et al. 2012). Dube et al. (2012) melaporkan adanya pola genetik yang meningkat pada sifat litter size dalam enam belas tahun program seleksi pada bangsa babi Large White di Afrika Selatan. Paura et al. (2014) juga melaporkan pola yang meningkat pada jumlah anak babi yang lahir hidup yang dilakukan pada bangsa babi Landrace dan Yorkshire.

Pendugaan nilai pemuliaan pada ternak babi di Indonesia saat ini sangat terbatas. Zhang et al. (2015) menyatakan pendugaan parameter genetik pada suatu populasi berbeda dengan populasi yang lain. Provinsi Bali sebagai salah satu sentra populasi ternak babi di Indonesia belum memiliki informasi mengenai parameter genetik yang memadai. Penelitian ini bertujuan untuk menduga 
parameter genetik dan pola genetik sifat reproduksi ternak babi di Provinsi Bali.

\section{MATERI DAN METODE}

\section{Sumber Data}

Data yang digunakan dalam penelitian ini yaitu data sekunder yang berasal dari UPT BIBD Baturiti Provinsi Bali dan data primer yang dikumpulkan melalui wawancara pengukuran secara langsung berkaitan dengan sifat reproduksi ternak babi terhadap peternak pengguna jasa IB yang menggunakan semen cair babi dari UPT. Data berasal dari recording UPT BIBD Baturiti dari tahun 2010 sampai dengan tahun 2015. Sedangkan pengumpulan data dilaksanakan pada bulan Januari-Maret 2016 di dua kabupaten yang mewakili Provinsi Bali yaitu Kabupaten Badung dan Kabupaten Tabanan sebagai tempat pengumpulan data. Penentuan lokasi berdasarkan wilayah dengan jumlah pengguna jasa IB tertinggi.

Data yang terkumpul berjumlah 180 data kelahiran yang meliputi 20 pejantan, 122 induk dan 1704 anak (Tabel 1). Data jumlah anak per induk per kelahiran (litter size), jumlah anak yang mati sebelum disapih (mortalitas) dan jumlah anak yang disapih. Data dikelompokan menjadi empat dimana setiap kelompok terdiri dari dua tahun kelahiran dikarenakan keterbatasan jumlah data. Data pada tahun 2010-2011, 2012-2013, 2014-2015 dan 2016 masing-masing berjumlah 18, 30, 98 dan 34 .

\section{Analisis Data}

Pendugaan nilai pemuliaan dihitung dengan menggunakan rumus berdasarkan Hardjsubroto (1994) disajikan sebagai berikut:

Keterangan:

Nilai Pemuliaan $=\mathrm{h}^{2}\left(\mathrm{P}_{i}-\bar{P}_{p}\right)$

$\mathrm{h}^{2} \quad$ : nilai heritabilitas litter size, mortalitas dan jumlah sapi

$\underline{P i} \quad$ : performa individu

$\bar{P}_{p}$ : rerata performa populasi di mana individu diukur

Pendugaan nilai korelasi genetik dan fenotipik dihitung dengan menggunakan rumus matematis berdasarkan Becker (1992) disajikan sebagai berikut:

$$
\begin{aligned}
& r g=\frac{\text { covo }}{\delta \mathrm{ox}^{2} \delta \mathrm{ey}^{2}} \\
& r p=\frac{\text { covo }+ \text { cove }}{\sqrt{\left(\delta^{2} \mathrm{ox}+\delta^{2} \mathrm{ex}\right) \times\left(\delta^{2} \mathrm{oy}+\delta^{2} \mathrm{ey}\right)}}
\end{aligned}
$$

\section{Keterangan}

o : peragam komponen genetik

e : ragam komponen sifat pertama

$\mathrm{x}$ atau $\mathrm{y}$ : ragam komponen sifat kedua
Pendugaan pola genetik dan fenotipik dengan rerata regresi antara pendugaan nilai pemuliaan dengan tahun kelahiran untuk setiap bobot badan dihitung dengan menggunakan rumus matematis berdasarkan Filho et al. (2005) disajikan sebagai berikut:

$$
\mathrm{Y}=\mathrm{a}+\mathrm{bX}
$$

Keterangan:

Y : litter size, mortalitas dan jumlah sapih

a : intersep/kemiringan

$\mathrm{X}$ : tahun kelahiran

$\mathrm{b}$ :koefisien regresi

\section{HASIL DAN PEMBAHASAN}

\section{Perbandingan Sifat Reproduksi}

Rerata sifat litter size, mortalitas pra sapih dan jumlah anak yang disapih masing-masing 9,161; 0,780 dan 8,382 ekor per kelahiran (Tabel 1). Rerata litter size pada penelitian ini lebih rendah dari laporan Klimas (2011) yaitu sebesar 11 ekor per kelahiran pada babi Landrace di Eropa, namun lebih tinggi dari laporan Aritonang dan Silalahi (2001) yang melaporkan litter size sebesar 8,4 ekor per kelahiran. Litter size yang lebih rendah berkaitan dengan faktor lingkungan pemeliharaan ternak tersebut (Suriyasomboon 2006). Einarsson et al. (2008) menyatakan bahwa suhu lingkungan yang tinggi dapat menurunkan litter size karena dapat mengurangi implantasi dan mengganggu perkembangan embrio babi . Knecht et al. (2013) menjelaskan lebih lanjut bahwa perbedaan suhu dan lama waktu pencahayaan dalam musim yang berbeda akan memengaruhi kesuburan ternak yang nantinya berpengaruh pada litter size.

Pada sifat mortalitas pra sapih pada penelitian ini memiliki rerata 0,780 per ekor per kelahiran atau 0,09\%. Hasil ini lebih rendah dengan laporan Aimonen et al. ( 2013) dan Li et al. (2010) yang melaporkan rerata mortalitas pra sapih lebih tinggi yaitu pada kisaran 12-14\% dan $18-24 \%$ pada bangsa Landrace dan Yorkshire. Gobai et al. (2013) menyatakan bahwa kemampuan induk dalam mengasuh anak babi dapat memengaruhi daya tahan anak babi hingga masa penyapihan. Stres akibat panas diantara anak babi dan penurunan jumlah pakan yang dikonsumsi induk babi selama musim panas dapan menurukan produksi susu sehingga berakibat pada kematian anak babi (Li et al. 2010).

Jumlah anak yang disapih pada penelitian ini sebesar 8,382 ekor. Nilai ini lebih tinggi dari Li et al. (2010) dan Aritonang dan Silalahi (2001) pada persilangan empat bangsa babi yaitu sebesar 7,53 ekor dan 6,6 ekor. Rensburg dan Spencer (2014) menyatakan bahwa pengaruh lingkungan terhadap jumlah anak yang disapih dapat ditekan dengan manajemen pemeliharaan yang baik. Manajemen pemeliharaan yang baik memengaruhi litter

Tabel 1 Data sifat reproduksi litter size, mortalitas pra sapih dan jumlah sapih pada ternak babi

\begin{tabular}{lccccc}
\hline Sifat & Jumlah Data & Rerata \pm SE & Koefisien Variasi & Min & Max \\
\hline Litter Size & 180 & $9,161 \pm 0,234$ & 34,79 & 1 & 18 \\
Mortalitas pra sapih & 180 & $0,780 \pm 0,104$ & 181,89 & 0 & 7 \\
Jumlah Sapih & 180 & $8,382 \pm 0,222$ & 36,12 & 0 & 16 \\
\hline
\end{tabular}


Tabel 2 Sepuluh pejantan terbaik berdasarkan nilai pemuliaan litter size, mortalitas pra sapih dan jumlah anak yang disapih

\begin{tabular}{|c|c|c|c|c|c|}
\hline \multirow[t]{2}{*}{ No. ID } & \multirow[t]{2}{*}{ Bangsa } & \multirow[t]{2}{*}{ Jumlah Kelahiran } & \multicolumn{3}{|c|}{ Nilai Pemuliaan (peringkat) } \\
\hline & & & Litter size (ekor) & Mortalitas (ekor) & Jumlah Sapih (ekor) \\
\hline 32 & $\mathrm{D}$ & 6 & $0,27(1)$ & $0,01(4)$ & $0,35(2)$ \\
\hline 34 & $\mathrm{~L}$ & 10 & $0,13(5)$ & $0,03(2)$ & $0,01(9)$ \\
\hline 28 & $\mathrm{D}$ & 15 & $0,14(4)$ & $0,04(1)$ & $-0,07(10)$ \\
\hline 37 & $\mathrm{D}$ & 10 & $0,13(6)$ & $0,01(3)$ & $0,10(7)$ \\
\hline 31 & $\mathrm{~L}$ & 7 & $0,27(2)$ & $-0,01(10)$ & $0,47(1)$ \\
\hline 35 & $\mathrm{~L}$ & 19 & $0,13(7)$ & $0,01(8)$ & $0,16(5)$ \\
\hline 30 & $\mathrm{D}$ & 15 & $0,21(3)$ & $-0,01(9)$ & $0,35(3)$ \\
\hline 5 & $\mathrm{D}$ & 6 & $0,05(10)$ & $0,01(5)$ & $0,01(8)$ \\
\hline 27 & $\mathrm{H}$ & 10 & $0,10(8)$ & $0,01(7)$ & $0,17(4)$ \\
\hline 33 & $\mathrm{~L}$ & 11 & $0,09(9)$ & $0,01(6)$ & $0,13(6)$ \\
\hline
\end{tabular}

$\mathrm{D}=$ Duroc; $\mathrm{L}=$ Landrace; $\mathrm{H}=$ Hampshire

size dan daya tahan anak babi sehingga meningkatkan jumlah anak yang disapih (Nienaber dan Hahn 2007). Sulabo et al. (2010) juga melaporkan bahwa pengaruh asupan makanan dan kemampuan induk dalam mengasuh anak berpengaruh terhadap jumlah anak yang disapih.

\section{Pendugaan Nilai Pemuliaan}

Pejantan dengan pendugaan nilai pemuliaan tertinggi pada litter size, mortalitas pra sapih, dan jumlah anak yang disapih disajikan pada Tabel 2. Nilai-nilai pemuliaan adalah nilai yang menunjukkan posisi individu dalam populasi (Kaygisiz 2013). Pejantan dengan nomor ID 32, 28, 31 memiliki nilai tertinggi pemuliaan untuk litter size $(0,27)$, mortalitas prasapih $(0,01)$ dan jumlah anak yang disapih $(0,35)$. Bangsa Duroc dan Landrace mendominasi pada peringkat pejantan terbaik. Aritonang dan Silalahi (2001) menyatakan bahwa kedua bangsa babi tersebut tergolong unggul di Indonesia. Pemilihan pejantan unggul dalam populasi untuk program seleksi dapat dilakukan dengan menggunakan kriteria nilai pemuliaan tertinggi karena diturunkan kepada generasi berikutnya. Setiap nilai diperoleh berdasarkan nilai pendugaan heritabilitas dikalikan dengan differensial seleksi (Becker 1992). Perbedaan peringkat muncul ketika ternak yang digunakan dalam menduga nilai pemuliaan untuk dua sifat atau lebih sebagai dasar kriteria seleksi menghasilkan nilai yang berbeda (Pena et al. 2004). Program seleksi dapat dilakukan pada sifat litter size maupun sifat jumlah anak yang disapih karena memiliki nilai pemuliaan yang tinggi.

\section{Korelasi Genetik dan Fenotipik}

Nilai korelasi fenotipik yang diperoleh dalam penelitian ini berkisar antara 0,16-0,92. Korelasi fenotipik tertinggi $(0,92)$ antara litter size dan jumlah anak yang disapih. Korelasi fenotipik positif yang sangat kuat antara litter size dan jumlah anak yang disapih lebih tinggi dari nilai yang diperoleh oleh Radojkovic et al. (2012) dan Rothschild (1996) yaitu 0,25 dan 0,66. Hal tersebut kemungkinan diakibatkan peningkatan jumlah anak babi yang lahir yang juga dapat meningkatkan jumlah babi disapih, bahkan pada nilai korelasi yang lemah sekalipun. Tur (2013) menyatakan penerapan sistem manajemen reproduksi induk yang baik sangat penting dalam kesuksesan program manajemen dan pencapaian efisiensi reproduksi. Hasil penelitian ini menunjukkan nilai korelasi yang negatif $(-0,14)$ pada mortalitas pra sapih dengan jumlah anak yang disapih dan korelasi rendah $(0,25)$ pada litter size dan mortalitas pra sapih. Korelasi yang rendah serta negatif antara sifat litter size dan jumlah anak yang disapih dengan mortalitas pra sapih tersebut merupakan hal yang baik karena korelasi antara sifat tersebut dapat menurukan jumlah anak yang mati sebelum disapih. Hasil ini sangat berguna dalam upaya mengatasi masalah kematian anak babi pra sapih.

Korelasi genetik antara sifat reproduksi berkisar antara -0,16-0,91 untuk litter size, mortalitas pra sapih untuk mortalitas dan jumlah anak yang disapih (Tabel 3). Korelasi genetik sesuai dengan pola pada korelasi fenotipik. Korelasi genetik antara mortalitas pra sapih dan jumlah anak yang disapih tergolong tinggi $(0,92)$. Korelasi yang tinggi tersebut mengindikasikan bahwa litter size yang tinggi akan menhasilkan jumlah anak yang tinggi pula. Hasil ini lebih tinggi dari hasil penelitian Radojkovic et al. (2012) dan Lukac dan Vidovic (2013) yaitu sebesar 0,331 dan 0,11. Hasil ini kemungkinan disebabkan oleh aksi gen yang pleiotropy pada kedua sifat memiliki pengaruh aditif, sehingga dapat diteruskan kepada keturunannya. Korelasi yang positif dan kuat antara litter size dan jumlah anak yang disapih mengindikasikan bahwa sifat-sifat tersebut dikontrol oleh gen yang sama dan jika seleksi dilakukan pada salah satu sifat maka akan membawa pengaruh positif pada sifat yang lain (Gunawan et al. 2012). Korelasi genetik antara litter size dan mortalitas tergolong rendah $(0,23)$ dan korelasi antara mortalitas pra sapih dan jumlah anak yang sapih memiliki korelasi negatif $(-0,16)$. Seleksi dapat dilakukan pada sifat litter size maupun jumlah anak yang disapih yang memiliki nilai korelasi yang kuat dan tinggi.

\section{Pola Genetik dan Fenotipik}

Pola genetik dan fenotipik sifat reproduksi termasuk litter size, mortalitas pra sapih dan jumlah anak

Tabel 3 Korelasi genetik (di bawah diagonal) and korelasi fenotipik (di atas diagonal) pada litter size, mortalitas pra sapih dan jumlah anak yang disapih

\begin{tabular}{lccc}
\hline Sifat Reproduksi & Litter Size & Mortalitas & Jumlah Sapih \\
\hline Litter Size & & 0,25 & 0,92 \\
Mortalitas & 0,23 & & $-0,14$ \\
Jumlah Sapih & 0,91 & $-0,16$ & \\
\hline
\end{tabular}


yang disapih antara tahun 2010-2016 ditunjukkan pada Gambar 1 dan 2. Pola fenotipik umumnya menunjukkan pola fluktuatif untuk semua sifat selama 2010-2016 (Gambar 1). Rerata terendah adalah sifat litter size pada tahun 2012-2013, setelah itu terjadi peningkatan sampai tahun 2015 kemudian menurun pada 2016. Selanjutnya, rerata nilai pemuliaan jumlah anak yang disapih meningkat tajam pada tahun 2015, namun terjadi penurunan setelah itu (Gambar 1). Pola fenotipik litter size positif 0,46 ekor/tahun. Berbeda dengan litter size, pola fenotipik untuk jumlah anak yang disapih meningkat masingmasing 0,02 dan 0,44 ekor per tahun (Tabel 4). Fluktuasi rerata nilai yang diamati untuk semua sifat reproduksi mengindikasikan lingkungan yang mungkin memainkan peran besar dalam kemampuan babi untuk menghasilkan anak babi di lokasi pemeliharaan (Gunawan et al. 2011).

Pola genetik untuk litter size dan jumlah anak yang disapih menurun pada 2012-2013 kemudian meningkat pada 2014-2015 dan menurun pada 2016
(Gambar 2). Hasil ini berbeda dengan laporan Kasprzyk et al. (2007) yang melaporkan pola yang meningkat untuk sifat litter size dan jumlah anak yang disapih. Perbedaan antara model dan metode perhitungan dan juga efek dari lingkungan dan faktor bangsa dapat memengaruhi pola genetik (Mondal et al. 2014; Tomiyama et al. 2011). Kecenderungan pola genetik yang konstan pada mortalitas prasapih antara 2010-2016 kemungkinan disebabkan oleh perilaku induk babi dalam mengasuh anak babi tersebut yang relatif sama setiap tahun. Canario et al. (2014) melaporkan bahwa perilaku induk saat mengasuh anak berkontribusi pada daya tahan anak babi sampai penyapihan. Pola genetik menunjukkan perkembangan negatif pada semua sifat-sifat reproduksi. Tingkat kemajuan genetik rendah untuk sifat reproduksi kemungkinan diakibatkan oleh dua faktor. Pertama, dalam program seleksi, penekanan lebih besar pada ciri-ciri kinerja bukan pada sifat reproduksi. Kedua, sifat-sifat ini umumnya memiliki heritabilitas rendah dan dapat

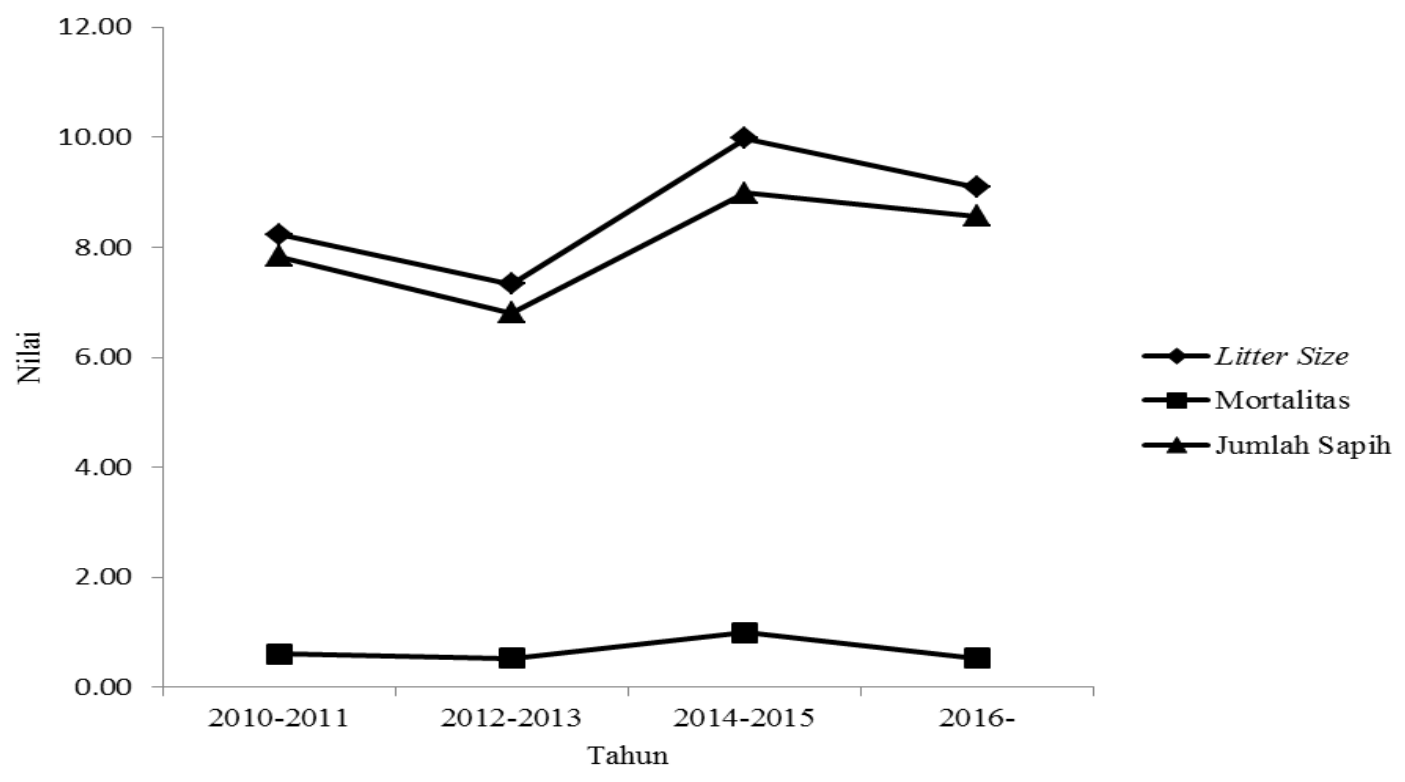

Gambar 1 Pola fenotipik litter size $\boldsymbol{\Lambda}$, mortalitas pra sapih $\mathbf{\square}$, dan jumlah sapih

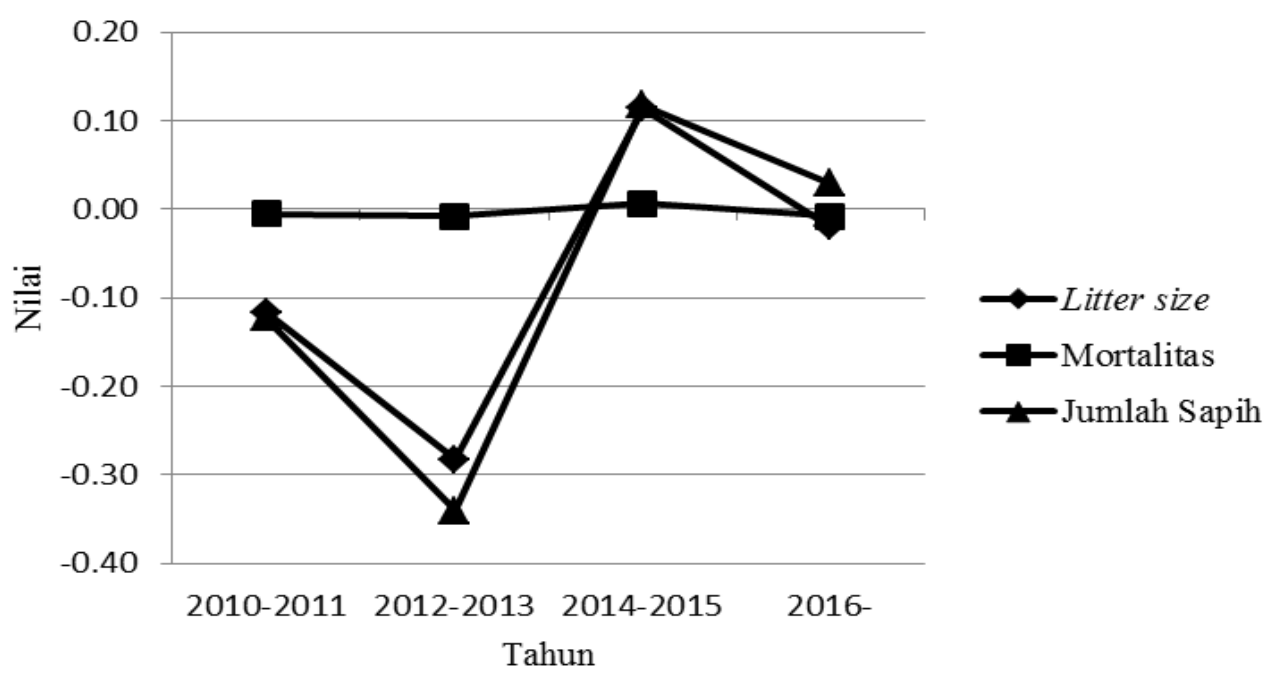

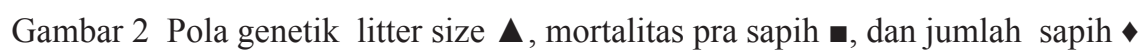


Tabel 4 Pola genetik dan fenotipik litter size, mortalitas prasapih dan jumlah anak yang disapih

\begin{tabular}{llc}
\hline & Persamaan Regresi & R2 \\
\hline Pola Genetik & Litter size $=-0,25+0,06$ X & 28,2 \\
& Mortalitas $=-0,01+0,00 \mathrm{X}$ & 1,6 \\
& Jumlah Sapih $=-0,31+0,09 \mathrm{X}$ & 34,7 \\
\hline Pola Fenotipik & Litter size $=7,57+0,46 \mathrm{X}$ & 28,2 \\
& Mortalitas $=-0,61+0,02 \mathrm{X}$ & 1,6 \\
& Jumlah Sapih $=6,95+0,44 \mathrm{X}$ & 34,7 \\
\hline
\end{tabular}

memperlambat kemajuan genetik (Gunawan et al. 2011).

\section{KESIMPULAN}

Korelasi genetik maupun fenotipik yang tinggi terdapat pada sifat litter size dan jumlah anak yang disapih. Pola genetik dan fenotipik dari tahun 2010 sampai tahun 2016 menunjukkan adanya pola yang fluktuatif pada litter size dan jumlah anak yang disapih. Sedangkan sifat mortalitas pra sapih menunjukkan pola yang stabil. Seleksi pada sifat litter size akan efektif dalam meningkatkan jumlah anak yang disapih.

\section{DAFTAR PUSTAKA}

Aimonen, M.L.S., P. Uimari. 2013. Heritability of sow productivity and lifetime prolificiacy in finnish Yorkshire and landrace pigs. Agric and Food Sci. 22: 325-330.

Aritonang, D., M. Silalahi. 2001. Produktivitas berbagai galur babi ras impor selama periode laktasi. JITV. 6(1):38-44.

Becker, W.A. 1992. Manual of Quantitative Genetics. Ed ke-5. Washington (US): Academic Enterprises.

Canario, L., H. Hundgren, H. Haandlykken, L. Rydhmer. 2014. Genetics of growth in piglets and the association with homogeneity of body weight within litters. J Anim Sci. 88:1240-1247.

Dube, B., D. Sendros, Mulugeta, K. Dzama. 2012. Estimation of genetic and phenotypic parameters for sow productivity traits in South African Large White pigs. South African J Anim Sci . 42 (4): 389-397

Einarsson, S., Y. Brandt, N. Lundeheim, A. Madej. 2008. Stress and its influence on reproduction in pigs: a review. Acta Vet Scand. 50(1):1-8. doi: 10.1186/1751-0147-50-48.

Filho, R.D.T., R. Torres, P. S. Lopes, C. S. Pereira, R. F. Euclydes, C. V. De araujo, M. Silva. 2005. Genetic trends in the performance and reproductive traits of pig. Gen Molec Bio. 28 :97-102

Gunawan, A., Jakaria. 2011. Genetic and non-genetics effect on birth, weaning, and yearling weight of bali cattle. Media Petern. 34(2):93-98. doi: 10.5398/ medpet.2011.34.2.93

Gunawan, A., R. Sari, Y. Parwoto. 2011. Genetic analysis of reproductive traits in bali cattle maintained on range under artificially and naturally bred. JITAA. 36(3):152-158.

Gunawan A, R. Sari, Jakaria. 2012. Estimates of Genetic and Phenotypic Trends of Growth Traits in Bali Cattle.
Media Petern. 35(2): 85-90.

Hardjosubroto, W. 1994. Aplikasi Pemuliabiakan Ternak di Lapangan. Jakarta (ID): PT Gramedia Widiasarana Indonesia.

Kasprzyk, A. 2007. Estimates of genetic parameters and genetic gain for reproductive traits in the herd of Polish Landrace sows for the period of 25 years of the breeding work. Arch Tierz Dummerstorf. 50:116-124.

Kaygisiz, A. 2013. Estimation of genetic parameters and breeding values for dairy cattle using test-day milk yield records. J Anim Plant Sci. 23(2): 345-349

Knecht, D., S. Srodo'n, K. Szulc, K. Duzi'nski. 2013. The effect of photoperiod on selected parameters of boar semen. Livest Sci. 157(1):364-371

Kiszlinger, H.N., J. Farkas, G. Kover, I. Nagy. 2013. Selection for reproduction traits in Hungarian pig breeding in a two-way cross. Anim Sci Pap Rep. 31 ( 4): 315-322.

Klimas, R., A. Klimiene. 2011. Performance traits in different generationsof imported Danish Landrace pigs. Archiv Tierzucht. 54 (2): 157-164.

Lee, J.H., K. D. Songla, H. K. Lee, K. H. Cho, H. C. Park, K. D. Park. 2015. Genetic parameters of reproductive and meat quality traits in korean berkshire pigs. Asian Australian J Anim Sci. 28 (10) : 1388-1393

Li, Y., L. Johnston, A. Hilbrands. 2010. Pre-weaning mortality of piglets in a bedded group-farrowing system. J Swine Health Prod. 18(2):75-80.

Lukac, D., V. Vidovic. 2013. Parameters of genetic and phenotypic type in pigs mating in pure breed and crossbreeding on litter size. Afr J Agric Res. 8(37):4664-4669.

Mondal, S.K., P. Amit, P.D. Kumar, B. Sivamani, T. Dutt. 2014. Estimation of variance and genetic parameters for pre-weaning weights of individual Landrace X Desi synthetic piglets. J App Anim Res. 42(3): 338344. doi: 10.1080/09712119.2013.875901

Newcom, D.W., T. J. Baas, K. J. Stalder, C. R. Schwab. 2005. Comparison of three models to estimate breeding values for percentage of loin intramuscular fat in Duroc swine. J. Anim. Sci. 2005. 83:750-756

Nienaber, J., G. Hahn. 2007. Livestock production system management responses to thermal challenges. Int J Biomet. 52:149-157.

Paura, L., D. Jonkus, U. Permanickis. 2014. Genetic parameters and genetic gain for the reproduction traits in Latvian Landrace and Yorkshire sows populations. Anim Vet Sci. 2(6): 184-188

Pena, C.D.O., R. Carvalheiro, S. A. Queiroz, L. A. Fries. 2004. Comparison of selection criteria for pre-weaning growth traits of Nelore cattle. Livest Prod Sci. 86: 163-167. http://dx.doi.org/10.1016/ S0301-6226(03)00164-7

Radojkovic, D., M. Petrovic, C. Radovic, N. Parunovic, M. Popovac, M. Gogic. 2012. Heritability and correlation of litter traits in pigs determined by reml method. Biotech Anim. Husband. 28 (4): 771-778. DOI: $10.2298 / \mathrm{BAH} 1204771 \mathrm{R}$

Rensburg, L.Jv., B. T. Spencer. 2015. The influence of environmental temperatures on farrowing rates and litter sizes in South African pig breeding 
units. Onderstepoort J Vet Res. 81(1):824. dx.doi. org/10.4102/ojvr. v81i1.824

Rothschild, M.F. 1996. Genetics and reproduction in the pig. Anim Reprod Sci. 42: 143- 151.

Sulabo, R.C., J. Y. Jacela, M. D. Tokach, S. S. Dritz, R. D. Goodband, J. M. DeRouchey, J. L. Nelssen. 2010. Effects of lactation feed intake and creep feeding on sow and piglet performance. J Anim Sci. 88:31453153 doi:10.2527/jas.2009-2131

Suriyasomboon, A., N. Lundeheim, A. Kunavongkrit, S. Einarsson. 2005. Effect of temperature and humidity on reproductive performance of crossbred sows in Thailand. Theriogenology. 65: 606-628

Tomiyama, M., S. Kubo, T. Takagi, K. Suzuki. 2011. Evaluation of genetic trends and determination of the optimal number of cumulative records of parity required in reproductive traits in a Large White pig population. Anim Sci J. 82: 621-626.

Tur, I. 2013. General reproductive properties in pigs. Turkish J Vet Anim Sci. 37:1-5

Zhang, T., L. Wang, H. Shi, H. Yan, Lc. Zhang, X. Liu, L. Pu, J. Liang, Y. Zhang, K. Zhao, L. Wang. 2015. Heritabilities and genetic and phenotypic correlations of litter 2 uniformity and litter size in Large White. J Integ Agric. 15(4): 848-854.

Zhu, M.J.J., T. Ding, B. Liu, M. Yu, B. Fan, C. C. Li, S. H. Zhao. 2008. Estimation of genetic parameters for four reproduction component traits in two chinese indigenous pig breeds. Asian-Aust J Anim Sci. 21(8): 1109-1115.

Ziedina, I., D. Jonkus, L. Paura. 2011. Genetic and Phenotypic Parameters for Reproduction Traits of Landrace Sows in Latvia. Agric Conspec Sci. 76(3):219-222.

Zishiri, O.T., S. W. P. Cloete, J. J. Oliever, K. Dzama. 2010. Genetic trends in South African terminal sire sheep breeds. S. Afr. J Anim Sci. 40 (1): 458 